\title{
THE HUMAN FACTOR IN LEARNING DESIGN, RESEARCH, POLICY, AND PRACTICE
}

\section{Introduction}

There are probably very few training and education practitioners who have not heard of 'Bloom's Taxonomy'. It is also possible that a large number of them have not read the original (Bloom et al., 1956) taxonomy and indeed, a significant proportion will likely not have explored any of the alternatives that have since been developed as a result of the very research which the authors encouraged six decades ago. Where this is the case, one may wonder why Bloom's (1956) taxonomy continues to inform the setting of learning objectives and the design of learning materials when the field of psychology from which Bloom and his colleagues drew their inspiration has moved on.

One possible reason for this situation is that where it arises institutional policies have failed to keep pace with recent research findings and incorporate them into practical guidelines for training and education practitioners. This case study is not a critique of Bloom et al. (1956); that has been done, many times. Instead, it uses it as a starting point for discussion about how research and policy can and should work together to maintain theoretical currency in the design of learning experiences which explicitly target human cognitive processes.

The case study is organised in two parts. The first provides a backdrop to the second and gives an account of recent research which takes the position that all tasks involve a level of cognitive engagement. A brief description of the emergence of learning design and its relationship with psychology is followed by examples of policy and the problem of dissonance. We then discuss cognitive theories of skill acquisition, learning, multimodal learning and their application to the development of learning technologies; an empirical comparative evaluation of an innovative training delivery method is presented. The second part of the paper starts by exploring, with reference to e-learning, the concept of linking research, policy and practice and the interactions between the human components of training and education systems - the 'human factor' (Salvendy, 2012). A model is described which links the human factor with effective learning design research, policy and practice.

\section{The Emergence of Learning Design}

From the early 1940s, psychologists started to explore how humans process information and analysis of the cognitive processes that underpin externally observable behaviour. The field of cognitive psychology has since grown exponentially and seen the development of many related branches and applications including military training and education. During the World War 2 psychologists combined the growing understanding of how individuals learn with systems engineering principles in order to develop effective mass training systems for the military.

The combination of a systems approach and cognitive psychology ultimately led to formation of instructional systems design (ISD) as a distinct academic discipline. Similar in concept to ISD but more broadly based, 'learning design' refers to the process of designing effective learning experiences for a variety of contexts: in the classroom or laboratory, in the field, online and via standalone packages using a range of media. Learning design involves a wide 
set of knowledge, skills and competencies, including learning theory and its applications, course design principles and procedures, use of media, use of different technologies, and relevant business processes (see MacLean \& Scott, 2007).

\section{Policy and Dissonance in the 'Human Factor'}

Learning design principles are deployed in large organisations and institutions with a requirement to train and educate their workforce or, in educational contexts, students (such as those encountered in the health and defence sectors). Typically policy states how training and education should align with strategic goals. For example, in the UK, the National Health System has set out a policy framework for education and training of its workforce (Department of Health, 2012). The Defence Systems Approach to Training (DSAT) governs the management, design, and delivery of training and education in line with 'good practice' in the civilian training world (MoD, 2012). The education sector is no different and most educational institutions have policy frameworks which include teaching and learning. Generally, training and education policies should address issues of assessing and constantly improving the quality of education, training, and skill development and deployment of validated and up-todate methods. However, policy and practice are two different matters and as Swift (2005) points out, introducing key theory which has the potential to fill significant gaps in practice takes time.

Swift's observation is not unique in terms of introducing valid theory or research into policy. In effect, there is often a dissonance between research, policy, and practice embodied in the relationships between and differing perspectives and motivations of academics, policymakers, and practitioners (Cherney et al., 2012). For example, it is often the case in defence training that training pipelines are focused on the acquisition of knowledge and skills. Competence and skill retention is not explicitly considered and this suggests that training equates to competence. However, research demonstrates that once acquired, skills are subject to decay (Arthur et al 1998; Wang et al., 2013). Therefore, an opportunity for training pipelines to consider acquisition and competence together exists but cannot be exploited, unless policy acts on the evidence from research and mandates its inclusion.

The above situation highlights the requirement for ongoing iterative review and development of policy against incoming validated research findings. In healthcare, Jansen et al. (2012) noticed that when actors across administrative, institutional and individual levels communicate research results clearly and work collaboratively and coherently to develop policy, more efficient and effective practice is achieved. Ansari \& Coch (2006) identify a number of obstacles facing effective collaboration between actors and levels including lack of a common background and common language but that overcoming them can bring significant benefits to all involved. This study explores how policy could address these issues and how the human factor might be re-aligned in producing evidence-based and practical policy.

\section{PART 1: Psychological Knowledge and Skill Domains}

When deciding on the training priorities for a task or job role, it is beneficial to have an understanding of the type of Knowledge, Skills and Attitudes (KSA) that are required to 
competently and successfully perform a task to the standard required Following the job analysis stage, the KSA analysis is performed. Here a military task is decomposed into the KSA that must be acquired in order to effectively perform the task or demonstrate the relevant task-related competences. DSAT recognises that in addition to knowledge, different types of skills exist and it presents a definition of these skills that are used when conducting a KSA analysis. However, the classification of KSA currently used in DSAT documentation is inconsistent with advances in the psychological literature. As a consequence, the accurate consideration of competence and the underlying knowledge and skills that need to be acquired and retained, and the factors that determine how this competence can be best trained and maintained, is constrained. Cahillane, et al. (2013) developed a re-classification of KSA, in terms of the psychological components (categories) of competence retention, referred to as psychological knowledge and skill domains. This re-classification defined KSA in a manner that is consistent with the psychological literature on knowledge and skills retention. Any job-related knowledge and skills can be aligned to this generic taxonomy of psychological domains which is summarised below.

\section{Outline of Domains}

Outlining the psychological domains that underpin the knowledge and skills or sub tasks (knowledge and different skills) enables the consideration of generic principles and guidance for the optimisation of their acquisition and retention.

Knowledge. Knowledge precedes all other skills, whether technical or non-technical in nature. However, the retainability of knowledge depends on the type of knowledge. Also, knowledge can be examined outside of its relationship with any other type of skill as a distinct category to be addressed in providing training interventions aimed at the acquisition and maintenance of competence.

Declarative knowledge. The first stage of learning addresses the development of declarative knowledge, e.g., what things are and why things work. Declarative knowledge includes facts, rules or information about a task and as such represents explicit knowledge. Performance of a task is thought to be based on the declarative knowledge that must be held in working memory during the execution tasks (Beilock \& Carr, 2004; Rhem, 2005). Declarative knowledge is developed through the presentation of new information being translated by the individual into propositions (ideas), associations and connections, which generates new connections and inferences (Rhem, 2005). Declarative knowledge can change with the acquisition of new information. Declarative knowledge is not conscious until it is retrieved using cues in the environment such as questions (Berge \& Hezewijk, 1999).

Procedural (skill-based) knowledge. The declarative knowledge gained at initial acquisition is further refined and converted into procedural knowledge to produce skill-based behaviour. Procedural knowledge refers to knowing the required actions and how to carry them out; hence the behaviour or task execution becomes more automatic (Ritter et al., 2011). Knowledge or information about a task is available in both declarative and procedural forms. At this stage, the procedural knowledge predominantly drives performance; this knowledge is made up of productions that represent knowledge about how we do things. Unlike declarative knowledge, procedural knowledge does not require the active maintenance of each step of task execution in working memory. 
Procedural skills. Many military activities are underpinned by the application of procedural skills, such as Standard Operating Procedures (SOP), drills and digital procedures to be followed in order to execute commands on complex software based systems (Cahillane \& Morin, 2012). Numerous research studies in cognitive psychology have demonstrated that tasks requiring the application of procedural skills are highly susceptible to skills decay. Tasks requiring the application of procedural skill have a number of coherent steps, which include the application of both cognitive and motor skills, although the motor element is minimal. Where the motor element is more prevalent a task would be representative of a discrete psychomotor skill.

Discrete and continuous psychomotor skills. Psychomotor skills can be classed as continuous or discrete. Continuous (open loop) skills are characterised by repeated actions or steps with no discrete initial or final steps, such as flying an aircraft or driving a vehicle (Arthur, 1998; Stothard \& Nicholson, 2001; Wisher et al., 1999; Wisher et al., 1991). Discrete psychomotor (closed loop) skills on the other hand are physical movements applied to tasks with discrete beginning and endings, which include sequences of steps. Stripping and assembling a rifle is a good example of a task requiring the application of discrete psychomotor skill. In this example, an individual is required to remember a sequence of component steps within a "Skill at Arms" drill, whilst performing the physical/motor component, of manipulating the respective parts and characteristics of the rifle.

Decision making skills. Decision-making skills involve the application of cognitive processes such as judgement, problem solving and analysis in order for an individual to arrive at a decision. Two tasks representative of these skills are troubleshooting faulty equipment (which involves the use of reasoning skills in order to identify the problem) and the interpretation of topographical maps to identify symbols with terrain features on the ground (Wisher et al., 1999).

Attitude. The attitude category is covered in terms of the behavioural attitudes and attributes which are representative of the role of the affective domain in learning. The taxonomy learning objectives in the cognitive domain developed by Bloom and others (Bloom et al., 1956 ) is still widely used by trainers and educators in Defence and other sectors. However, we draw upon Anderson et al.'s revision (2001) of the original 1956 "Bloom's Taxonomy " that identified the cognitive and metacognitive knowledge dimensions and processes and recognised that most cognitive training objectives will have an attitudinal component. Notwithstanding this point, if addressing the attitude component of KSA, specification of attitudes into training objectives should be limited to those observable attitudinal behaviours that are essential to the task or desired performance. This is because it is difficult to specify training objectives for attitudes that are not directly observable. Behavioural anchors reflecting attitudes towards safety, quality of performance, cultural awareness, etc., can be described and observed.

In contexts where no observable attitudes can be described, at least meaningfully, the KSA analysis and specification of training objectives should be concentrated upon the knowledge and skills domains. Attitudes should be considered in terms of attributes which moderate learning and competence retention. These should be inculcated at both the organisational and individual level. Therefore, the affective domain (Krathwohl et al., 1964) is considered in terms of a framework of psychological attributes that drive self-regulation of learning. Many 
of these attributes can be trained and observed for example, the skills of planning, selfmonitoring, evaluation and motivation.

\section{Learning Theory and Skills Acquisition}

Deliberate practice and rehearsal is required in order for psychomotor procedural skills to be successfully acquired. When physical practice is not possible, for whatever reason, simulation-based practice and instruction can provide a learner with the opportunity for structured mental rehearsal of a skill providing effective feedback on performance outcomes. Moreover, detailed immediate information feedback stemming from a learner's performance, combined with a chance to improve performance, is important to skills acquisition (Issenburg et al., 2005; Wang et al., 2008).

\section{Context-Dependent Memory}

Context-dependent memory refers to the observation that people are better at remembering information if they either return to the environment in which it was encoded (learned) or imagine the environment in which they acquired the information (Anderson, 1983; Godden \& Baddeley, 1975; Raaijmakers \& Shriffrin, 1981). Smith and Vela (2001) demonstrated that when people who are associated with the learning context are the same at encoding and retrieval, more information is correctly retrieved. Smith and Vela argue distinctive faces and voices associated with the environment at encoding serve as cues for the later successful retrieval of information and thus maintenance of knowledge and skills.

\section{Mental Practice}

Several studies in the scientific literature have reported that mental practice, also known as rehearsal, enhances performance (Driskell et al., 1994; Lee, 1990; Rogers, 2006) and can benefit the acquisition and maintenance of tasks with a cognitive element. There are different types of cognitive tasks. For example, cognitive tasks are higher order cognitive tasks that require the application of decision-making type skills such as reasoning, evaluation, judgement and problem solving. However, here we are referring to those with a procedural component, that is, where a sequence of steps has to be retained. Mental practice can be defined as the cognitive rehearsal of a physical procedural activity in the absence of overt physical movements being conducted (Richardson, 1967; Driskell et al., 1994). Physicalprocedural tasks relate to discrete psychomotor tasks that have discrete beginnings and endings and require the memorization of sequenced steps. Research has indicated that new learning technologies can support the acquisition and retention of skills, in particular those that have a procedural component (Cahillane \& Maclean, 2014).

In order for mental practice to be effective, it must take place when the learner is already familiar with the task and has thus received hands-on practice during training (Rogers, 2006). An example of mental practice applied to a discrete psychomotor task is a soldier thinking a drill through and visualising the steps in the sequence required to perform the drill successfully. In this instance, mental practice of physical drills and handling procedures can be supported by technology in the form of multi-modal PC-based learning (Cahillane \& Maclean, 2014). According to Cahillane et al., research has indicated that new learning technologies can support the acquisition and retention of skills, in particular those that have a procedural component. The impact of mental practice on performance is lower than that which is observed with physical hands-on practice but has been found to have a moderate and significant effect on performance (Driskell et al. (1994). Driskell et al. observed that 
mental rehearsal was effective for both cognitive and physical tasks. Furthermore, the more a task is comprised of cognitive elements, the more of an influence mental practice has on performance for that task. Moreover, those less experienced at a task benefit more from mental practice when that task is cognitive than they do when the task is mostly physical.

\section{Physical vs. Psychological Fidelity}

In a comprehensive and practical set of guidelines, Stone $(2008,2012)$ makes several evidence-based recommendations for the design of immersive 3-dimensional and Virtual Environments (VE) for training either as game-based simulations or part-task trainers. Foremost among these is the need to address fidelity issues, that is, the extent to which the simulated environment represents the real world. For example, physical fidelity is concerned with how well the virtual environment mimics the appearance of the real-world counterpart. This is contrasted with psychological fidelity, which is "the degree to which simulated tasks reproduce behaviours that are required for the actual, real-world target application" (Stone, 2012, p.6) and which Stone associated more closely than physical fidelity with transfer of training. The physical and psychological attributes of military VPTTS or games-based training environments require attention to four key classes of fidelity: task fidelity, context fidelity, hypo- and hyper-fidelity, and interactive technology fidelity.

\section{The Modality Effect and Learning with Media}

Moreno \& Mayer's (2007) model of cognitive-affective learning with media depicts how visual and auditory instructional materials are processed from presentation, into working memory and finally to integration with long-term memory. Addressing modality (e.g., presenting learning materials in dual format with explanations as an auditory narration rather than visually as onscreen text) is one of the principles of good multimedia (MM) design recommended by Clark and Mayer (2002). The key feature of the modality effect is that the audio/visual instructional sources of information presented to the learner have to refer to and support each other and must be processed together in order to be intelligible. Materials that are designed to take advantage of the modality effect by presenting onscreen audio and visual information together are superior to those in a visual only format and reduce cognitive load (Leahy \& Sweller, 2011).

The principles referred to above tend to be used only for what has so far been referred to as multimedia or multimodal design of instructional materials. However, the term bimodal should probably be used when addressing dual sensory channels (auditory and visual) just as unimodal may refer to text only materials. True multimodal learning, then, would address other sensory channels. One such modality is the pressure modality, which receives information through passive exploration known as tactile perception. Haptic perception refers to the process of actively exploring stimuli in the learning environment. Technologies delivering haptic in addition to audio and visual information and feedback would better represent multimodal learning. Inclusion of olfactory information in simulated or virtual environments is currently of limited interest to defence training but odour may have a role. Stone (2012) suggested three possible scenarios for military training: odour could create an ambience effect in urban patrol training or be used to simulate the smell of burning in safety critical maritime simulations as well as detection of fluid or vapour leakages. 


\section{Virtual Part-Task Trainers (VPPTs)}

In light of the above discussion of knowledge, learning theory, and skills acquisition it is argued that when physical practice is not possible, owing to factors such as reduced availability of equipment for "hands on" training, simulation-based practice and instruction can provide an opportunity for maintaining key skills, in particular those with a procedural component. Moreover, simulation-based practice and instruction can support structured mental practice through encouraging and coaching learners in visualising the tasks to be retained.

Part-Task Trainers (PTTs) may be used to develop critical sub-skills prior to more comprehensive training either in a simulator or on live equipment (Wightman \& Lintern, 1983). PTTs are used to train limited aspects of a task rather than providing an integrated learning experience (Gaba, 2004). Part-task training is intended to provide more efficient training often with the aim of reducing cost. VPPTs provide 3D interactive equipment simulations to assist in the acquisition of new skills and knowledge through familiarisation and practice. They can function on various platforms such as personal computers (PCs), interactive whiteboards, tablet PCs, and mobile devices. Interaction with a PC-based VPTT is achieved through use of a computer mouse, keyboard, and/or touchscreen. VPTTs can be designed with a high degree of detail depending on the learning objectives and required levels of physical and psychological fidelity.

\section{Research}

Cahillane \& Maclean, (2014) carried out an empirical comparative evaluation of an innovative training delivery method intended to support the acquisition of weapon handling drills. The authors describe research involving a prototype PC-based MM tool developed to gather evidence for optimising a blend of training delivery methods and media that could be used for the acquisition of psychomotor procedural skills. The prototype was designed as an aid to the evaluation of the underlying concepts and principles of learning design and was not intended to enter service. HTML and JavaScript were used to present text, video and images within the MM tool. Interactive formative assessments and feedback were included to stimulate the cognitive processes involved in learning. The use of multimodal cues designed into the materials was intended to enhance learning and performance. Audio, images, and video were used and the voice of a trained instructor included helping the learners associate the drills to be learned with the familiar auditory commands originally heard in the classroom and thus the required movements. The psychological nature of many of the drills being trained using the tool are representative of the discrete psychomotor skills typically required in many tasks trained using VPTTs, i.e., they have a procedural and perceptual-motor element.

\section{Learning Design Opportunities}

The theory and research discussed in this study are intended to promote deeper consideration for the evidence of effects in using a range of technologies to target cognitive learning processes and support categories of psychological skill referred to above while taking into account how the human cognitive system encodes, stores and retrieves information. An understanding of the cognitive mechanisms that underpin learning is important when designing technology to support skill acquisition and maintenance, which 
must be congruent with the cognitive capabilities of the user. Dror (2008) specifically noted how it is often perceived that technology drives learning when the focus should be on using technology to support the acquisition and maintenance of knowledge and skills. When writing specifications for new learning technologies, developers should not only understand the task to be trained but be provided with a clear breakdown of the training objectives. Developers and learning designers should clearly indicate to the learner what the Key Learning Points (KLPS) and Intended Learning Objectives (ILOs) are and how these will be covered by the technology in question (Clark \& Mayer, 2011). It is important to focus on the learner and not solely the technology and materials or animations.

The principles for learning design that harness mental processes involved when learning from a two-dimensional, dual-channel environment are still highly relevant to the design of elearning materials. When a principle-based approach that addresses human cognition and technology is applied, the intended learning is more likely to occur. During the research an evaluation of two technological packages intended for revision and reinforcement of weapon handling drills (see Cahillane \& Maclean, 2014) highlighted the importance of applying the principles in the revision and retention of psychomotor procedural skills in the design of VPTTs. In this case, the use of multimodal information, including the presence of the operator hands manipulating the equipment, enhanced performance by enabling learners to associate auditory commands with the required movements. The need to base multimodal design on the psychology of human learning and behaviour is extended in the guidance for design of immersive three-dimensional and games-based training systems (see Stone, 2008, 2012).

A significant output of the authors' studies into the use of MM and VPTTs was recognizing the importance of a handling human, or at least representations of human hands carrying out more difficult manipulation tasks. Qualitative data gathered from participant feedback suggest that such a human presence improves engagement with the materials and understanding of the tasks to be learned. The results from the trial suggest that incorporation of additional MM materials such as interactive video should be considered in the design of future VPTTs seeking to train similar skills. Thus, it would include the best features of both types of approach and support not only the acquisition of knowledge about the VPTT subject matter, but also that for how to carry out a greater diversity of discrete psychomotor tasks. How this research can be used strategically in a form of inclusive and collaborative policy-making intended to drive effective practice is explored below.

\section{PART 2: Policy and Practice}

\section{Strategy, Policy and e-Learning}

In his analysis of strategy and what it might mean Mintzberg comes to the conclusion that the most useful view of strategy is as a perspective that focusses attention on the reflections and actions of the 'collectivity' of people that is the organisation pursuing a common mission and "how intentions diffuse through a group of people to become shared as norms and values, and how patterns of behaviour become deeply ingrained in the group" (Mintzberg, 1987, p.21). Different organisations will have their own views of what strategy may be but a common one is that strategy starts with a vision of the organisation's intentions. The means by which the organisation diffuses its intentions is generally a combination of strategic 
statements of intent e.g., a corporate plan and framework of policies which detail the courses of action (or, as Codd (1988) points out, 'inaction') required to achieve the stated strategic aims.

Training and education institutions usually have some form of vision and corporate plan including teaching and learning strategies and policy frameworks. Where an institution identifies a requirement for e-learning it seems reasonable to assume that within the overall strategy and policy framework there is an e-learning strategy or policy providing direction, a coherent approach, and sustained commitment to the use of technology in teaching and learning. However, these are missing in many institutions currently investing in e-learning and therefore they have little to show in terms of change and progress in this area (Garrison, 2011). In response to these shortcomings Garrison proposes a set of topics that should be included in an e-learning policy document and strategic plan along with clear descriptions of educational principles and outcomes for e-learning. These will likely include principles similar to those presented in the first part of this study. But, until they become systemically and flexibly integrated into the organisation's practice and culture, driven by committed leadership, supported by middle managers and those above and below them, they will unfortunately remain what Phillips (2005) describes as mere rhetoric and far removed from practice.

Without infrastructure, knowledge, guidance, and the opportunity to participate in institutional change practitioners will continue unchallenged to do what they have always done - for the better or the worse of the quality of learning and teaching within the institution and the experiences of its students. However, e-Learning policy can drive change but it must first overcome resistance while staff make sense of it and attempt to evaluate the impact of change on their practice (De Freitas \& Oliver, 2005).

\section{Adaptable Learning for Practice, Policy-making and Change}

Evaluating the impact of change is not a new idea among recent generations of teachers. During their training they will have been introduced to critical and systematic thought processes relating to change and improvement of practice through reflection and action research. They will understand how researching personal practice results in intellectual and professional development while simultaneously contributing to organisational improvement (e.g., Zuber-Skerrit, 1992; McNiff et al., 2003; Coghlan \& Brannock, 2005). In addition to generating personal theory about practice, they may value the use of theory from research on learning and teaching and be able to distinguish between sound evidence and 'neuromyths' - misconceptions about brain functioning which can lead to ineffective or adverse educational practice e.g., learning styles, left/right brain thinking (see Dekker et al., 2012; Howard-Jones, 2014). Familiar concepts might include single and double-loop learning (see, Ashby, 1954; Argyris \& Schön, 1974), the latter of which assists in challenging such micsconceptions and avoiding bias.

Single-loop learning is found in set patterns of individual and organisational behaviour and expectations of maintaining a stable state. Double-loop learning promotes deeper learning, change, and effect; it avoids constancy, is responsive, and can be used for managing 
instability in many contexts including those where strategic direction and policy are missing or ineffective. Like Bloom's original taxonomy, these fundamental ideas are often misapplied but unlike Bloom's original, it is arguable that they retain validity as principles for, learning, development and managing change or, conversely, maintaining constancy where policy requires no action to be taken. Double-loop learning results from adjusting what Argyris \& Schön (1974) refer to as "governing variables" or rules, values, theories and concepts and which underpin a situation. It is, in Ashby's (1954) terms, the equivalent of the householder changing the thermostat's base setting and therefore the overall temperature.

E-Learning policy is a form of governing variable. Practitioners who understand the principles of double-loop learning, reflection on action (i.e., analysis of and acting upon the outcomes of practice), change, and research play an essential part in policy-making and implementation to effect systemic change. They, along with others, can identify or generate evidence from research which informs policy, contributes to a knowledge-base, and creates and maintains a link with practice. Policy, teachers (practitioners and trainees), educational programmes for administrators, and general beliefs people hold about learning and teaching form paths which mediate the link between research and practice; a link which must be strengthened (Bransford et al., 2001).

\section{Motivation and Engagement}

Similar paths or relationships appear within Conole's (2010) framework of interdependent factors of policy embedded in strategy, research development changing user behaviour, the learner's experience and collecting evidence of impact, and teacher practice. Conole's model also includes the importance of addressing the 'what's in it for me?' (WIIFM) of teachers and avoiding the repetition of 'depressingly classic mistakes' such as over-emphasis on technologies and not people and processes, and funding for technology developments but not use and support (Conole, 2010, p.22). Race (2014) reminds us of the need to also point out to learners their 'WIIFM' and help them to take ownership of what they are doing including pointing out the benefits of doing it successfully; pointing out the benefits is equally important in policy development.

Articulating 'WIIFM' and benefits at all levels is key in motivating people to engage with change and engage in well-informed action. In this respect, Dormant's (1992) model of change agency remains relevant as is the need for identifying and appointing credible and committed 'champions' who can overcome resistance through argument and promotion of collaboration and discussion. Champions should be able to interact with and win over stakeholders; they play an important role in generating flexible, evidence-driven policy and practice which produces further evidence, and constructs knowledge for current and future practice and evaluation of learning.

\section{Alignment of Research, Policy, and Practice}

In Part 2 we have discussed how e-learning strategy can align with the strategic aims of the organisation by combining research-generated evidence that feeds into flexible and responsive policy-making. This then guides effective practice the evaluation of which can generate evidence to inform policy and practice decisions and contribute to a growing body 
of knowledge. Successful alignment requires leadership and engagement of stakeholders at all levels (administrative, institutional, and individual) who value and are willing to contribute to evidence-based policy and practice. Figure 1 proposes a model which outlines the key components and relationships between research, policy, practice, and stakeholders which when reinforced could improve the quality of learning and teaching with technology. The model is intended as a basis for discussion about how to address the common problem of reducing dissonance and disconnects among all people involved in research, policy, and practice.

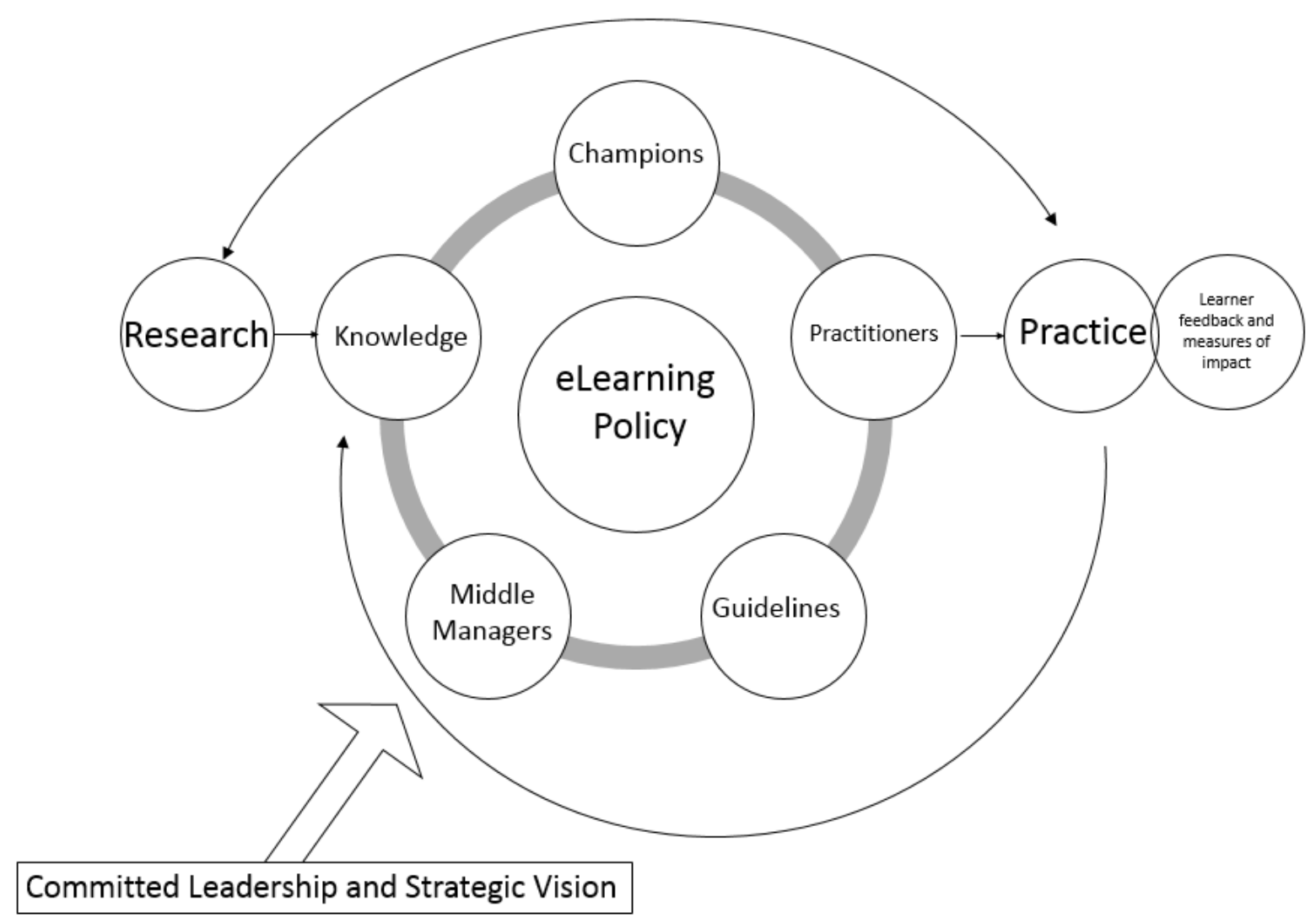

Figure 1: Proposed model for aligning research, policy, and practice driven by committed leadership, supported by middle managers and champions and engaged practitioners.

\section{Concluding remarks}

The case study began by describing a common phenomenon to illustrate how in learning and teaching research, theory and practice are often disconnected. This was illustrated with a discussion of the type of research that reflects how advances in cognitive science might inform existing policy. The coherence and quality of interactions between actors involved in policy and the systems within which they sit are essential to successful implementation and maintenance of policy. With respect to e-learning policy, alignment of all factors requires committed leadership, individuals willing to embrace evidence-based practice, and collaborative, mindful effort at all levels.

The ideas presented are, like the phenomenon described at the outset, probably familiar to many in training and education. In a small group using technology for training and education 
the issues raised are probably relatively unproblematic. However, at the institutional level, strategy, current evidence-based policy and communication are vital to success. This is where Bloom et al. (1956) make an enduring point. Although the taxonomy has moved on, the message remains the same - the need for a common language for describing and understanding and avoiding 'meaningless platitudes and clichés' (Krathwohl, Bloom, \& Masia, 1964 , p.4). Such a language would facilitate development of a framework for effective activity and communication. What we recommend is improved collaboration and communication supported by ongoing evaluation of policy such that policy becomes a dynamic process, a 'living' document which remains congruent with developments in the learning sciences. The model presented in this study is intended to promote thoughtful discussion about the processes and framework necessary for this to happen.

\section{References}

Ansari, D., \& Coch, D. (2006). Bridges over troubled waters: education and cognitive neuroscience. Trends in Cognitive Sciences, 10(4), 146-151.

Argyris, C., \& Schön, D. (1974). Theory in practice: Increasing professional effectiveness. San Francisco: Jossey Bass.

Ashby, R. (1954). Design for a Brain. New York: John Wiley \& Sons, Inc.

Anderson, J. R. (1983). A spreading activation theory of memory. Journal of Verbal Learning and Verbal Behavior, 22, 261-295.

Anderson, L. W., Krathwohl, D. R., Airasian, P. W., Cruikshank, K. A., Mayer, R. E., Pintrich, P.R., ... Wittrock, M. C. (2001). A taxonomy for learning, teaching, and assessing: A revision of Bloom's Taxonomy of Educational Objectives, (abr., 2nd ed.). Boston, MA: Allyn \& Bacon.

Arthur, W. Jr., Bennett, W. Jr., Stanush, P. L., \& McNelly, T.L. (1998). Factors that influence skill decay and retention: A quantitative review and analysis. Human Performance, 11, 57-101.

Beilock, S. L., \& Carr, T. H. (2004). From novice to expert performance: Attention, memory, and the control of complex sensorimotor skills. In A. Williams, N. Hodges, M. Scott, \& M. Court (Eds.), Skill acquisition in sport: Research, theory and practice (pp. 309-328). Routledge: London.

Berge, T., \& Hezewijk, R. (1999). Procedural and declarative knowledge: An evolutionary perspective. Theory \& Psychology, 9(5), 605-624.

Bloom, B. S., Engelhart, M., Furst, E. J., Hill, W.H., \& Krathwohl, D. R. (1956). Taxonomy of educational objectives: Handbook I: Cognitive domain. New York: David McKay.

Bransford, J., Brown, A. L., Cocking, R. R., \& National Research Council. Committee on Developments in the Science of Learning. (2000). How people learn: brain, mind, experience, and school. Washington, D.C.: National Academy Press. 
Cahillane, M., \& MacLean, P. (2014, July). Drill acquisition in weapon handling: Evaluating the effectiveness of an experimental multimedia tool. Proceedings of the International Conference on ICT in Education 2014. Kos, Greece.

Cahillane, M., \& Morin, C. (2012). Skills retention in a complex battlefield management system. Journal of Battlefield Technology, 15(1), 65-72.

Cahillane, M., Launchbury, C., MacLean, P., \& Webb, S. (2013). Competence retention (Report to UK MoD. STC_12_T_T2_001_1.1/005 Farnborough). Defence Human Capability Science and Technology Centres (DHCSTC).

Cahillane, M., Morin, C., Maclean, P., \& Stone, R. (2012). Sequence acquisition in weapon handling (Unpublished report to UK MoDAndover). Human Factors Integration - Defence Technology Centre (HFI DTC).

Cherney, A., Povey, J., Head, B., Boreham, P., \& Ferguson, M. (2012). What influences the utilisation of educational research by policy-makers and practitioners?: The perspectives of academic educational researchers. International Journal of Educational Research, 56, 23-34.

Clark, R., \& Mayer, R. (2002). E-learning and the science of instruction: Proven guidelines for consumers and designers of multimedia learning. San Francisco: Jossey Bass.

Codd, J. A. (1988). The construction and deconstruction of educational policy documents. Journal of Education Policy, 3(3), 235-247.

Coghlan, D., \& Brannick, T. (2005). Doing action research in your own organization. (2nd ed.). London;Thousand Oaks: Sage Publications.

Conole, G. (2010). Bridging the gap between policy and practice: A reflective review and looking forward to the future. Journal of E-Learning and Knowledge Society, 6(1), 13-27.

Dekker, S., Lee, N. C., Howard-Jones, P., \& Jolles, J. (2012). Neuromyths in Education: Prevalence and Predictors of Misconceptions among Teachers. Frontiers in Psychology, 3, 1-8.

De Freitas, S., \& Oliver, M. (2005). Does e-Learning Policy Drive Change in Higher Education?: A case study relating models of organisational change to e-learning implementation. Journal of Higher Education Policy and Management, 27(1), 81-96.

Department of Health. (2012). Liberating the NHS: Developing the healthcare workforce from design to delivery. Retrieved from: http://hee.nhs.uk/2012/08/07/liberating-the-nhsdeveloping-the-healthcare-workforce-from-design-to-delivery/

Dormant, D. (1992). Implementing human performance technology in organizations. In H.D. Stolovitch \& E.J. Keeps (Eds.) Handbook of human performance technology. San Francisco: Jossey-Bass.

Driskell, J. E., Copper, C., \& Willis, R. P. (1992). Effect of over learning on retention. Journal of Applied Psychology, 77(5), 615-622.

Dror, I. E. (2008). Technology enhanced learning: The good, the bad, and the ugly. Pragmatics and Cognition, 16 (2), 215-223. 
Gaba, D. (2004). The future vision of simulation in health care. Quality \& Safety in Health Care, 13(Suppl 1), i2-i10.

Garrison, D. R. (2011). E-Learning in the 21st Century: A Framework for Research and Practice. New York: Routledge.

Godden, D.R., \& Baddeley, A.D. (1975). Context-dependent memory in two natural environments: On land and underwater. British Journal of Psychology, 66, 325-331.

Howard-Jones, P. A. (2014). Neuroscience and education: myths and messages. Nature Reviews Neuroscience, advance online publication. doi:10.1038/nrn3817

Issenburg, S., McGaghie, W.C., Petrusa, E., Lee, G., \& Scalese, R. (2005). Features and uses of high fidelity medical simulations that lead to effective learning: a BEME systematic review. Med Teach, 27, 10-28.

Krathwohl, D. R., Bloom, B. S., \& Masia, B. (1964). Taxonomy of educational objectives: Handbook II: Affective domain. London: Longmans, Green.

Leahy, W., \& Sweller, J. (2011). Cognitive load theory, modality of presentation and the transient information effect. Applied Cognitive Psychology, 25(6), 943-951.

Lee. C. (1990). Psyching up for a muscular endurance task: Effects of image content on performance and mood state. Journal of Sport and Exercise Psychology, 12, 66-73.

MacLean, P., \& Scott, B. (2007). Learning design: requirements, practice and prospects. Campus-Wide Information Systems, 24(3), 187-198.

McNiff, J., Lomax, P., \& Whitehead, J. (2003). You and your action research project. (2nd ed.). London; New York: RoutledgeFalmer.

Ministry of Defence. (2012). Governance and management of defence individual training, education and skills (JSP 822). Retrieved from: https://www.gov.uk/government/publications/jsp-822-governance-and-management-ofdefence-individual-training-education-and-skills

Mintzberg, H. (1987). The strategy concept 1: five p's for strategy. California Management Review, 3, 11-23.

Moreno, R., \& Mayer, R. (2007). Interactive multimodal learning environments. Educational Psychology Review, 19(3), 309-326.

Phillips, R. (2005). Challenging the primacy of lectures: The dissonance between theory and practice in university teaching. Journal of University Teaching \& Learning Practice, 2(1), 2.

Rhem, A. J. (2005). Developing knowledge management systems. New York, NY: Auerbach Publications.

Richardson, A. (1967). Mental practice: A review and discussion, Part 1. Research Quarterly, 33, 95-107.

Ritter, F., Baxter, G., Kim, J., \& Srinivasmurthy, S. (2013). Learning and retention. In J. Lee., \& A. Kirlik, A. The Oxford handbook of cognitive engineering (pp.125-142). New York, NY: Oxford. 
Rogers, R.G. (2006). Mental practice and acquisition of motor skills: Examples from sports training and surgical education. Obstet Gynecol Clin N Am, 33, 297-304.

Salvendy, G. (2012). Handbook of Human Factors and Ergonomics. John Wiley \& Sons.

Smith, S. M., \& Vela, E. (2001). Environmental context-dependent memory: A review and meta-analysis. Psychonomic Bulletin and Review, 8, 203-220.

Stone, R.J. (2008). Human factors guidelines for interactive 3D and games-based training systems design: Edition 1. Human Factors Integration Defence Technology Centre Publication. Retrieved from www.hfidtc.com.

Stone, R.J. (2012). Human factors guidance for interactive 3D and games-based training systems design: Edition 2. Human Factors Integration Defence Technology Centre Publication. Retrieved from www.hfidtc.com.

Stothard, C., \& Nicholson, R. (2001). Skill acquisition and retention in training: DSTO support to the army ammunition study. Land Operations Division Electronics and Surveillance Research Laboratory. (DSTO-CR-0218).

Wang, E. E., Quinones, J., Fitch, M. T., Dooley-Hash, S., Griswold-Theodorson, S., Medzon, R., ... Clay, L. (2008). Developing technical expertise in emergency medicine--the role of simulation in procedural skill acquisition. Academic Emergency Medicine: Official Journal of the Society for Academic Emergency Medicine, 15(11), 1046-1057.

Wang, X., Day, E. A., Kowollik, V., Schuelke, M., \& Hughes, M. (2013). Factors influencing knowledge and skill decay after training: a meta-analysis. In W. J. Arthur, E. A. Day, W. J. Bennett, \& A. M. Portrey (Eds.), Individual and team skill decay: The science and implications for practice (pp. 68-116). New York, NY: Routledge.

Wightman, D. C., \& Lintern, G. (1983). Part-task training of tracking in manual control. Technical Report NAVTRAEQUIPCEN IH-347.

Wisher, R., Sabol, M., \& Ellis. J. (1999). Staying sharp: Retention of military knowledge and skills (Final Special Report 39):US Army Research Institute for the Behavioural and Social Sciences. Alexandria, VA.

Wisher, R., Sabol, M., Sukenik, H., \& Kern, R. (1991). Individual ready reserve (IRR) call-up: Skill decay (Research Report 1595). Alexandria, VA.: U.S. Army Research Institute for the Behavioral and Social Sciences.

Zuber-Skerritt, O. (1992). Action research in higher education: examples and reflections. London: Kogan Page. 